\title{
Chronic Subdural Hematoma Associated with Middle Fossa Arachnoid Cysts
}

-Three Case Reports-

\author{
Yoshihisa OKa, Yoshiaki KUMON, Shinsuke OHTA, Saburo SAKAKI, \\ Shiro OHUE*, and Sadanori TAKEDA**
}

Department of Neurological Surgery, Ehime University School of Medicine, Ehime;

*Department of Neurological Surgery, Washokai Sadamoto Hospital, Matsuyama;

**Department of Neurological Surgery, Saiseikai Imabari Hospital, Imabari, Ehime

\begin{abstract}
Three patients with chronic subdural hematoma associated with middle fossa arachnoid cyst were treated by irrigating the hematoma through burr holes, because the symptoms were considered mainly due to increased intracranial pressure caused by the subdural hematoma. The symptoms disappeared immediately afterwards, so no surgery for the middle fossa arachnoid cyst was done. The patients were followed by magnetic resonance imaging. No subdural hematoma recurred during a postoperative period of 11 months to 2.5 years, and the arachnoid cyst reduced in size in two patients. We recommend irrigation of the subdural hematoma as the initial procedure of choice for such cases.
\end{abstract}

Key words: subdural hematoma, arachnoid cyst, irrigation

\section{Introduction}

Chronic subdural hematoma develops in $16 \%$ of patients with a middle fossa arachnoid cyst, but especially in younger patients. ${ }^{4)}$ The most common symptom is headache without neurological abnormalities. ${ }^{2,17)}$ The pathogenesis involves the cyst, but there is no general agreement on the best method of surgery, with craniotomy $y^{1,13,16)}$ and trephination ${ }^{6,7)}$ both proposed as the optimum approach.

Here, we report three patients with middle fossa arachnoid cyst who developed chronic subdural hematoma, which was successfully treated by only irrigation of the hematoma through burr holes.

\section{Case Reports}

Case 1: A 17-year-old male was admitted with right temporal headache persisting for a few days following a head injury received 3 months previously. On admission, he had no neurological deficits and laboratory studies, including coagulation screening, were negative. $T_{1}$-weighted magnetic resonance (MR)

Received April 5, 1993; Accepted July 23, 1993 images showed right frontotemporal subdural hematoma associated with a middle fossa arachnoid cyst appearing as isointense masses (Fig. 1 upper). At surgery, the subdural hematoma was irrigated through burr holes. The symptoms disappeared immediately afterwards. $T_{1}$-weighted $M R$ images 16 days postoperatively showed that the right frontotemporal subdural space and the right middle fossa arachnoid cyst were of similar high intensity (Fig. 1 middle), suggesting rebleeding into these regions. However, no surgery was undertaken because he was asymptomatic. $\mathrm{T}_{1}$-weighted MR images 10 months after the operation showed that the right subdural hematoma had disappeared and the arachnoid cyst appeared as a low-intensity area of reduced size (Fig. 1 lower). No recurrence of subdural hematoma was detected at 2 years and 5 months postoperatively.

Case 2: A 24-year-old male was admitted with severe headache but without a past history of head injury. On admission, he had no neurological deficits and laboratory studies, including coagulation screening, were negative. $T_{1}$-weighted $M R$ images showed that the subdural hematoma appeared as a mixed, markedly and moderately high-intensity area while the arachnoid cyst was isointense (Fig. 2 upper). The 

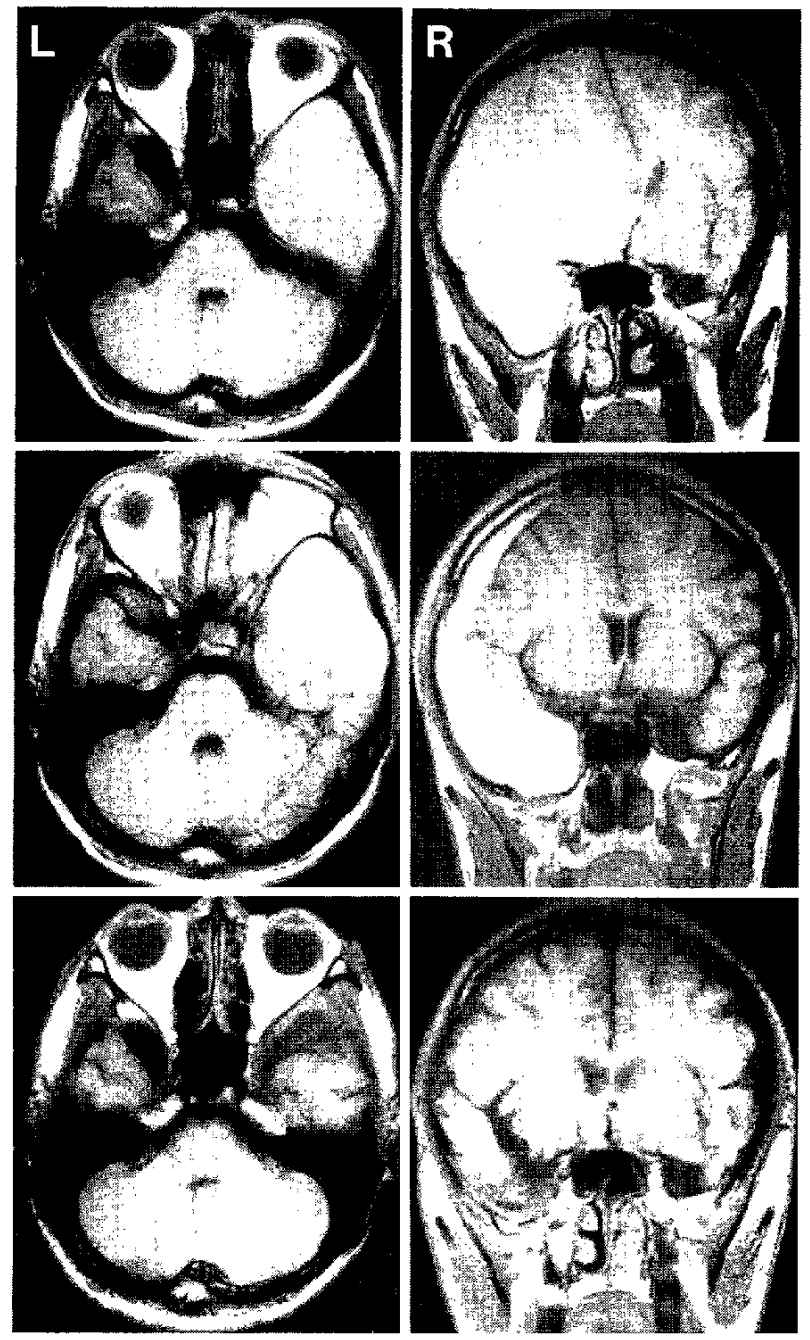

Fig. 1 Axial (left $)$ and coronal (right) $\mathrm{T}_{1}$-weighted MR images of Case 1. upper: On admission, showing both the hematoma in the subdural space and the middle fossa arachnoid cyst as isointense masses. middle: Sixteen days after operation, showing the hematoma in both sites as high intensity but reduced in size. lower: Ten months postoperatively, showing disappearance of the subdural hematoma and further reduction in the cyst size.

subdural hematoma was irrigated through burr holes. His headache disappeared completely postoperatively. $T_{1}$-weighted $M R$ images 9 days postoperatively showed that the subdural hematoma had mostly disappeared and the arachnoid cyst had became low intensity (Fig. 2 middle). Consequently, we considered that the hematoma in the arachnoid cyst had been adequately treated by the irrigation of the subdural hematoma. $T_{1}$-weighted MR images 5 months after the operation showed that the intensity of the arachnoid cyst was even lower (Fig. 2 lower). No recurrence of subdural hematoma had occurred by 2 years and 1 month postoperatively.

Case 3: A 13-year-old male complained of headache, nausea, and poor physical activity following a head injury received 2 months previously. He consulted a local doctor. $\mathrm{T}_{1}$-weighted $\mathrm{MR}$ images revealed an isointense hematoma in the left temporoparietal subdural space with a midline shift to the right, and an isointense mass in the left middle fossa suggesting an arachnoid cyst (Fig. 3 upper). He was then referred to our department. Neurological examination found slight right hemiparesis. Laboratory studies, including coagulation screening, were negative. At surgery, the subdural hematoma was irrigated through burr holes. His symptoms disappeared immediately afterwards. $T_{1}$-weighted MR images 9 days postoperatively showed that the left subdural hematoma markedly decreased in size but its intensity had became higher. In addition, the middle fossa arachnoid cyst slightly decreased in size but had become markedly high intensity indicating intracyst hemorrhage had occurred (Fig. 3 middle). $\mathrm{He}$ was observed without further surgical intervention, since his symptoms were completely relieved. $T_{1}$ weighted MR images 3 months after the operation showed that the subdural hematoma had disappeared and the arachnoid cyst appeared as low intensity with markedly decreased size (Fig. 3 lower). No recurrence of subdural hematoma had occurred by 11 months after the operation.

\section{Discussion}

Chronic subdural hematoma associated with an arachnoid cyst may result from: 1) the increased possibility of bleeding from unsupported vessels around the cyst and abnormal veins bridging the widened Sylvian fissure after even relatively minor trauma, ${ }^{9,12)}$ and 2) torn arachnoid membranes after minor trauma forming subdural effusion, which may be transformed into a chronic subdural hematoma. ${ }^{8}$ Such mechanisms suggest that removal of the membrane of the arachnoid cyst and evacuation of the subdural hematoma by craniotomy are logical procedures. However, irrigation of the subdural hematoma through burr holes is also reported to be adequate. ${ }^{6,7)}$ In our patients, the clinical symptoms were considered due to the chronic subdural hematoma, so only irrigation through burr holes was performed, and the arachnoid cyst was closely monitored by MR imaging. There was no detected recurrence of subdural hematoma for up to 2.5 

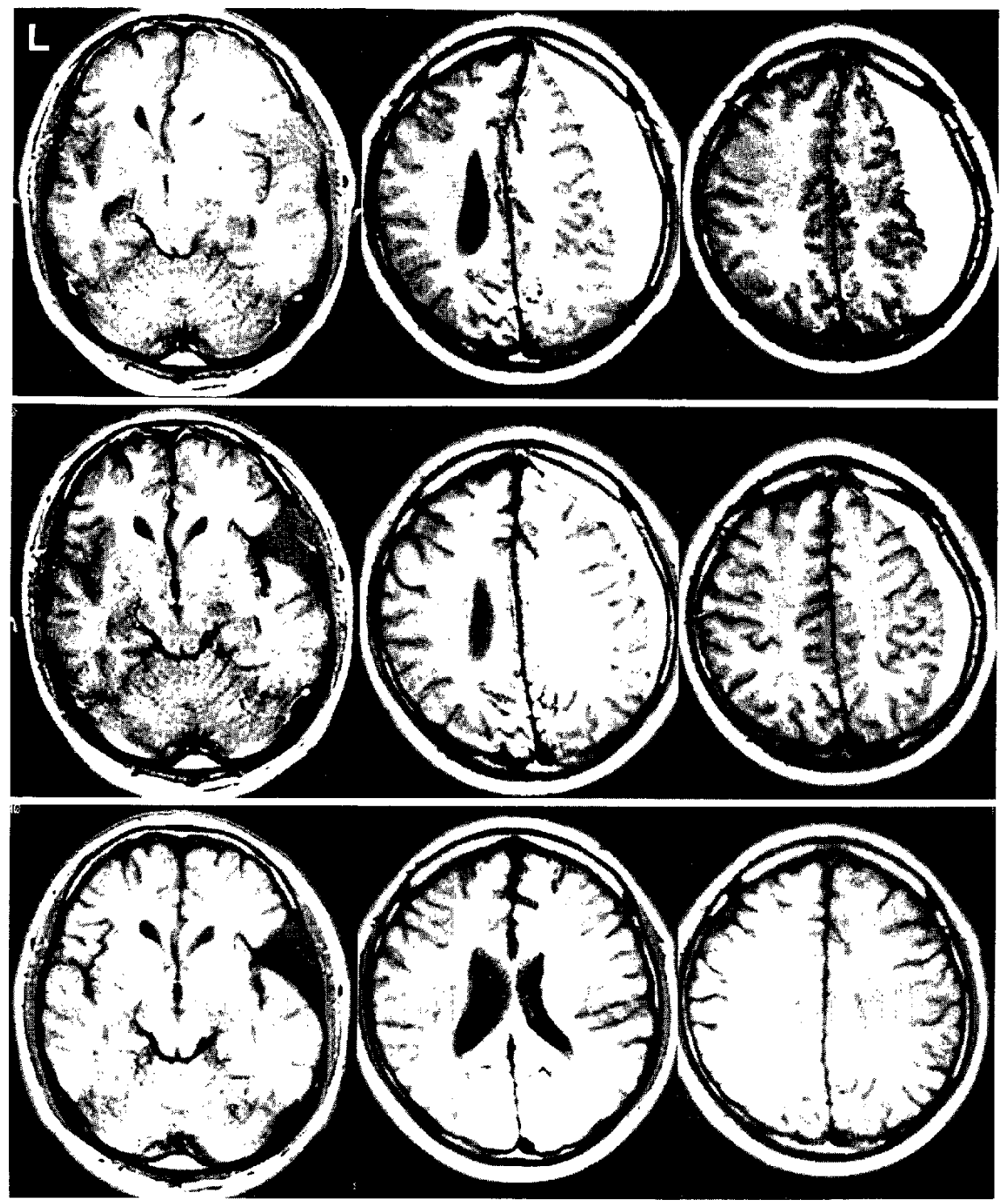

Fig. $2 \mathrm{~T}_{1}$-weighted MR images of Case 2. upper: On admission, showing the arachnoid cyst as isointense and the right temporoparietal subdural hematoma as high-intensity areas. middle: Nine days after operation, showing the arachnoid cyst as low intensity and reduced subdural hematoma. lower: Five months postoperatively, showing the arachnoid cyst as lower intensity and disappearance of the subdural hematoma.

years.

Only irrigation through burr holes has been performed in 18 patients including ours (Table 1). ${ }^{3,6,7,10-}$ ${ }^{16)}$ Four patients required craniotomy to resolve the arachnoid cyst because of rebleeding into the subdural space ${ }^{14)}$ or fluid retention in the subdural space or under the scalp. ${ }^{13,16)}$ The other patients achieved a good outcome with only the irrigation procedure, but few follow-up MR images have been reported. We followed our three patients by MR imaging. The
MR images of two patients showed that the arachnoid cyst was reduced in size at 3 or 10 months postoperatively. These findings suggest that the chance of recurring chronic subdural hematoma formation is low. ${ }^{5)}$

We suggest that chronic subdural hematoma associated with arachnoid cyst should be treated by irrigation of the subdural hematoma, followed by observation with MR imaging to detect rebleeding in the subdural space and arachnoid cyst if the symptoms are 


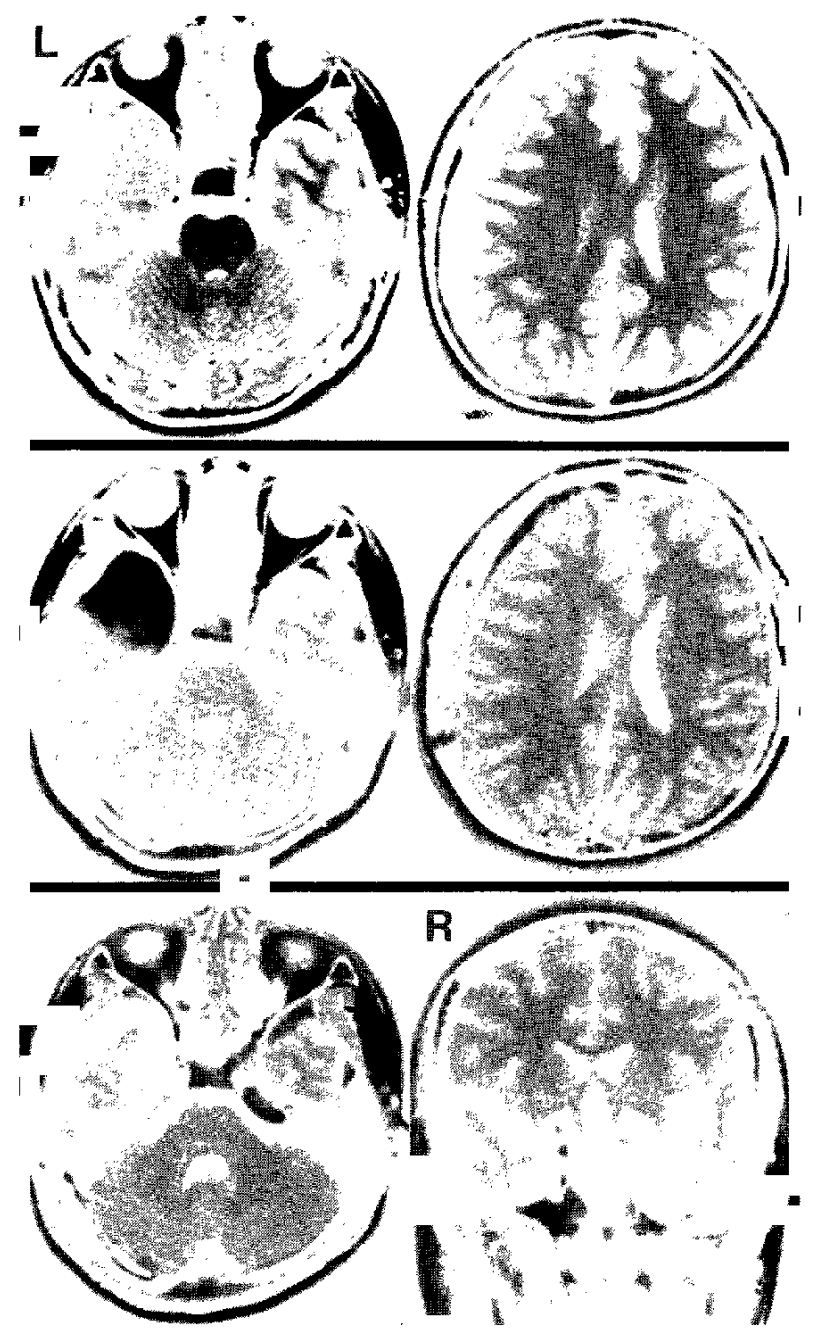

Fig. $3 \mathrm{~T}_{1}$-weighted $\mathrm{MR}$ images of Case 3. upper: Two weeks before admission, showing a left temporoparietal subdural hematoma and arachnoid cyst as isointense. middle: Nine days after operation, showing the subdural hematoma and arachnoid cyst as high intensity but both reduced in size. lower: Three months postoperatively, showing disappearance of the subdural hematoma and the arachnoid cyst as low intensity and reduced size.

resolved. Craniotomy may be required if the symptoms are not sufficiently relieved after irrigation, or massive rebleeding in the subdural space occurs following the initial operation.

\section{References}

1) Auer LM, Gallhofer B, Ladurner G, Sager W-D, Heppner F, Lechner H: Diagnosis and treatment of
Table 1 Eighteen cases of subdural hematoma associated with arachnoid cyst treated only by irrigation

\begin{tabular}{|c|c|c|c|c|}
\hline $\begin{array}{l}\text { Case } \\
\text { No. }\end{array}$ & Author (Year) & $\begin{array}{l}\text { Age/ } \\
\text { Sex }\end{array}$ & $\begin{array}{l}\text { Rebleeding or } \\
\text { retention into } \\
\text { subdural space }\end{array}$ & $\begin{array}{l}\text { Follow-up } \\
\text { period }\end{array}$ \\
\hline 1 & $\begin{array}{l}\text { Smith and Smith } \\
(1976)^{13)}\end{array}$ & $9 / \mathrm{M}$ & + & 2 wks \\
\hline 2 & $\begin{array}{l}\text { Varma et al. } \\
\left((1981)^{16)}\right.\end{array}$ & $7 / \mathrm{M}$ & + & $4 \operatorname{mos}$ \\
\hline 3 & & $7 / \mathrm{M}$ & + & $1 \mathrm{wk}$ \\
\hline 4 & $\begin{array}{l}\text { Nabeshima et al. } \\
(1982)^{11)}\end{array}$ & $7 / \mathrm{M}$ & - & 8 yrs \\
\hline 5 & $\begin{array}{l}\text { Kadowaki et al. } \\
(1983)^{6)}\end{array}$ & $11 / \mathrm{M}$ & - & $6 \operatorname{mos}$ \\
\hline 6 & $\begin{array}{l}\text { Tajima et al. } \\
(1984)^{14)}\end{array}$ & $12 / \mathrm{M}$ & + & $10 \mathrm{mos}$ \\
\hline 7 & & $26 / \mathrm{M}$ & - & $2 \operatorname{mos}$ \\
\hline 8 & $\begin{array}{l}\text { Takanohashi et al. } \\
(1986)^{15)}\end{array}$ & $15 / \mathrm{M}$ & - & $\begin{array}{l}3 \mathrm{yrs} \\
5 \mathrm{mos}\end{array}$ \\
\hline 9 & & $15 / \mathrm{M}$ & - & 1 yr $8 \mathrm{mos}$ \\
\hline 10 & Page et al. $(1987)^{12)}$ & $17 / \mathrm{M}$ & - & \\
\hline 11 & & $12 / F$ & - & \\
\hline 12 & Endo et al. $(1988)^{3)}$ & $16 / F$ & - & $\begin{array}{l}2 \text { yrs } \\
9 \mathrm{mos}\end{array}$ \\
\hline 13 & & $7 / F$ & - & $\begin{array}{l}3 \text { yrs } \\
2 \text { mos }\end{array}$ \\
\hline 14 & $\begin{array}{l}\text { Munk et al. } \\
\quad(1988)^{10)}\end{array}$ & $23 / \mathrm{M}$ & - & \\
\hline 15 & $\begin{array}{l}\text { Kamiura and Oka } \\
(1990)^{7}\end{array}$ & $25 / \mathrm{M}$ & - & $\begin{array}{l}1 \mathrm{yr} \\
3 \mathrm{mos}\end{array}$ \\
\hline 16 & Present Case 1 & $17 / \mathrm{M}$ & + & $\begin{array}{l}2 \mathrm{yrs} \\
5 \mathrm{mos}\end{array}$ \\
\hline 17 & Present Case 2 & $24 / \mathrm{M}$ & - & $\begin{array}{l}2 \text { yrs } \\
1 \text { mo }\end{array}$ \\
\hline 18 & Present Case 3 & $13 / \mathrm{M}$ & + & $11 \operatorname{mos}$ \\
\hline
\end{tabular}

middle fossa arachnoid cysts and subdural hematomas. $J$ Neurosurg 54: 366-369, 1981

2) Cappelen J, Unsggaard G: Arachnoid cysts of the middle cranial fossa and traumatic complications. Childs Nerv Syst 2: 225-227, 1986

3) Endo G, Matsumoto M, Yamazaki $T$, Kuroki $T$, Seki T, Terao H: Temporal fossa arachnoid cyst associated with chronic subdural hematoma. Clinical analysis of 7 cases. Shinkei Gaisho 11: 160-166, 1988 (in Japanese)

4) Galassi E, Piazza G, Gaist G, Frank F: Arachnoid cysts of the middle cranial fossa. A clinical and radiological study of 25 cases treated surgically. Surg Neurol 14: 211-219, 1980

5) Inoue $T$, Matsushima $T$, Tashima $S$, Fukui M, Hasuo $\mathrm{K}$ : Spontaneous disappearance of a middle fossa arachnoid cyst associated with subdural hematoma. Surg Neurol 28: 447-450, 1987

6) Kadowaki H, Ide $M$, Takara E, Yamamoto $M$, Imanaga $\mathrm{H}$, Jimbo $\mathrm{M}$ : A case of arachnoid cyst associated with chronic subdural hematoma. No Shinkei Geka 11: 431-436, 1983 (in Japanese)

7) Kamiura $\mathrm{T}$, Oka $\mathrm{H}$ : A case of chronic subdural hematoma associated with arachnoid cyst. Teikyo 
Igaku Zasshi 13: 261-266, 1990 (in Japanese)

8) Kusuno K, Yoshida Y, Takahashi A, Ishii S: Chronic subdural hygroma caused by rupture of arachnoid cyst. As a probable course to chronic subdural hematoma: Case report. Neurol Med Chir (Tokyo) 24: 349-354, 1984 (in Japanese)

9) LaCour F, Trevor R, Carey M: Arachnoid cyst and associated subdural hematoma. Observations on conventional roentgenographic and computerized tomographic diagnosis. Arch Neurol 35: 84-89, 1978

10) Munk PL, Robertson WD, Durity FA: Middle fossa arachnoid cyst and subdural hematoma. CT studies. J Comput Assist Tomogr 12: 1073-1075, 1988

11) Nabeshima S, Makita $Y$, Motomochi M, Itagaki T, Tei T, Keyaki A: Three cases of arachnoid cysts associated with chronic subdural hematoma. No To Shinkei 34: 173-178, 1982 (in Japanese)

12) Page A, Paxton RM, Mohan D: A reappraisal of the relationship between arachnoid cysts of the middle fossa and chronic subdural hematoma. $J$ Neurol Neurosurg Psychiatry 50: 1001-1007, 1987

13) Smith RA, Smith WA: Arachnoid cysts of the middle cranial fossa. Surg Neurol 5: 246-252, 1976

14) Tajima $K$, Saito $Y$, Nagai $K$, Takeda $Y$, Miwa $T$,
Hasue M, Ito Y: Clinical analysis of six cases of arachnoid cysts associated with chronic subdural hematomas or intracystic hemorrhage. Shinkei Gaisho 7: 123-130, 1984 (in Japanese)

15) Takanohashi M, Amano $Y$, Mizutani $T$, Tanoi $C$, Akabane A: Three cases of arachnoid cyst of the middle cranial fossa associated with subdural hematoma. Shizuoka Saiseikai Byoin Igaku Zasshi 4: 9-18, 1986 (in Japanese)

16) Varma TRK, Sedzimir CB, Miles JB: Post-traumatic complications of arachnoid cysts and temporal lobe agenesis. J Neurol Neurosurg Psychiatry 44: 29-34, 1981

17) von Wild K, Gullotta F: Arachnoid cyst of the middle cranial fossa. Aplasia of temporal lobe? Childs Nerv Syst 3: 232-234, 1987

Address reprint requests to: Y. Oka, M.D., Department of Neurological Surgery, Ehime University School of Medicine, Shizukawa, Shigenobu-cho, Onsen-gun, Ehime 791-02, Japan. 